\title{
Radiotherapy of Oligoprogressive Lesions in Castration-Resistant Prostate Cancer: Impact on Second-Generation Hormone Therapy
}

\author{
Kanta Ka1*, Papa Macoumba Gaye ${ }^{1,2}$, Awa Sadikh Badiane1, Ibrahima Thiam1, \\ Mouhamadou Bachir Ba1, Papa Massamba Diene', Maimouna Mané1, Lamine Niang2, \\ Fatou Samba Ndiaye ${ }^{2,3}$ \\ ${ }^{1}$ Radiotherapy Department of Centre Hospitalier National Universitaire Dalal Jamm, Guédiawaye, Senegal \\ ${ }^{2}$ Cheikh Anta Diop University of Dakar, Dakar, Senegal \\ ${ }^{3}$ Hematology Department of Centre Hospitalier Universitaire Dalal Jamm, Guédiawaye, Senegal \\ Email: *ka.kanta04@gmail.com, macoumba.gaye@gmail.com, awasadikh@gmail.com, ibathiam29@gmail.com, \\ mbbachir21@gmail.com,pamassdiene@gmail.com, maimouna.mane@hotmail.fr, nianglamine72@yahoo.fr, \\ kinepierre1@gmail.com
}

How to cite this paper: Ka, K., Gaye, P.M., Badiane, A.S., Thiam, I., Ba, M.B., Diene, P.M., Mané, M., Niang, L. and Ndiaye, F.S. (2021) Radiotherapy of Oligoprogressive Lesions in Castration-Resistant Prostate Cancer: Impact on Second-Generation Hormone Therapy. Journal of Cancer Therapy, 12, 302-310.

https://doi.org/10.4236/jct.2021.125028

Received: April 13, 2021

Accepted: May 28, 2021

Published: May 31, 2021

\section{Copyright $\odot 2021$ by author(s) and} Scientific Research Publishing Inc. This work is licensed under the Creative Commons Attribution International License (CC BY 4.0).

http://creativecommons.org/licenses/by/4.0/

(c) (i) Open Access

\begin{abstract}
Background: The therapeutic standard for oligoprogressive prostate cancer resistant to castration is second-generation hormone therapy. This systemic treatment is expensive. There are oligoprogressive lesions accessible to radiotherapy. Objectives: To study the impact of radiotherapy of oligoprogressive lesions on the implementation of second generation hormone therapy. $\mathrm{Pa}$ tients and Methods: A retrospective study from 2012 to 2020 was carried out. All patients with oligoprogressive prostate cancer who had received radiotherapy on one or more lesions in progression were collated. Survival was calculated using the Kaplan-Meier method. Results: 8 patients were treated with stereotactic and conformational radiotherapy between August 2012 and August 2020 in the context of oligoprogressive prostate cancer resistant to castration. The median age at diagnosis of oligoprogression was 73 years with a median PSA level of $3.11 \mathrm{ng} / \mathrm{ml}$. Nine lesions were diagnosed with PET scan PSMA. All the lesions were treated by radiotherapy with different regimens. After a median follow-up of 12.5 months, 7 patients showed a biochemical response to treatment with a median decrease in PSA of $67 \%$. The median survival without clinical or biochemical progression was 7 months. The median survival without the need for further systemic treatment was 9 months. During the follow-up period, six patients received second-generation hormone therapy to treat their relapse, and the other two showed no clinical or biochemical relapse. Conclusion: Radiotherapy may be an alternative to delay the introduction of difficult-to-access second-generation hormone thera-
\end{abstract}


py in developing countries. A prospective study could validate this therapeutic approach.

\section{Keywords}

Ablative Radiotherapy, Hormone Therapy, Oligometastasis, Prostate, Castration-Resistant Cancer

\section{Introduction}

Worldwide, prostate cancer is the second most common cancer in men and the fifth most common cause of cancer death in men [1]. Despite the efficacy of local treatments for the primary disease, 35\% of patients will develop metastatic disease from their prostate cancer during follow-up, whether discovered at initial diagnosis or at relapse. After an initial phase of sensitivity to castration, the evolution is inevitably towards the establishment of resistance to castration, which leads to a deterioration in the prognosis of the patients [2] [3].

The value of aggressive treatment of all metastatic disease in oligometastatic patients resistant to castration remains debated. There is insufficient evidence to suggest that aggressive management of the entire metastatic disease would delay the initiation of new systemic therapy. There is also no clear evidence of a benefit in terms of recurrence-free survival or overall survival.

We report here the results of patients treated with ablative and conformal stereotactic radiotherapy for oligometastatic progression of castration-resistant prostate cancer. The clinical benefits, in terms of biochemical recurrence-free survival and survival without the introduction of new systemic therapy, are outlined.

\section{Patients and Methods}

\subsection{Patients}

We retrospectively collected data on patients treated in our Institution from August 2012 to August 2020 with ablative and conformal stereotactic radiotherapy for oligometastatic evolution of castration-resistant prostate cancer.

The concept of oligometastatic cancer has evolved since the theory of Halsted et al. in 1894. Indeed, Hellman and Weichselbaum identified oligometastasis as a biological intermediate between localised cancer and polymetastatic cancer with the possibility of localised treatment [4]. Oligoprogressive cancer, on the other hand, corresponds to the progression of a limited number of lesions under systemic treatment [5].

Oligoprogressive prostate cancer is defined as a total of three or fewer progressive lesions either at known metastatic sites and/or the occurrence of new metastases and/or local recurrence [6].

Since the concept of Helman et al., numerous studies have suggested that ablative therapy can significantly improve prognosis and even lead to a cure [7] [8] 
[9].

Castration resistance has been defined as a significant increase in PSA (prostate specific antigen) verified on 3 consecutive measurements despite effective castration as evidenced by a testosterone level below $50 \mathrm{ng} / \mathrm{dl}$ or $1.7 \mathrm{nmol} / 1$ [10].

PSA is measured during surveillance of prostate cancer patients every 6 months until 5 years after local treatment.

Patients who were treated with second-generation hormone therapy prior to radiotherapy and/or whose hormone therapy was performed at most one week after localized ablative therapy were excluded.

\subsection{Diagnosis of Oligoprogression}

PSMA photon emission computed tomography (PSMA PET) imaging was used to identify the oligoprogressive lesion(s).

\subsection{Treatment}

All progressive lesions visible on imaging were treated with stereotactic or conformal radiotherapy with ablative intent, using one of the following hypofractionated regimens:

- $10 \mathrm{~Gy} \times 3$ fractions.

- $4 \mathrm{~Gy} \times 5$ fractions.

- $12 \mathrm{~Gy} \times 3$ fractions.

- $23 \mathrm{~Gy} \times 2$ fractions.

\subsection{Statistical Analysis}

The statistical analyses were carried out using SPSS 25 software. (IBM, U.S.A).

For each patient, we identified the criteria of clinical interest (initial stage, existence of local treatment of the primary, PSA level at the time of castration-resistant oligoprogression) and calculated the clinical or biochemical progressionfree survival as well as the survival without introduction of a new systemic treatment.

Progression-free survival (PFS) was calculated from the last day of radiotherapy treatment to clinical and/or biochemical progression.

Survival without the introduction of new systemic therapy was calculated from the last day of treatment to the date of initiation of new systemic therapy with 2nd generation hormone therapy.

\section{Results}

From August 2012 to August 2020, 8 patients were treated with ablative and conformal stereotactic radiotherapy at Gustave Roussy for oligoprogression of castration-resistant prostate cancer.

\subsection{At the Time of Initial Diagnosis (Table 1)}

The median age was 70 years. The median PSA level at initial diagnosis was 25.1 
ng/ml. In 3 patients, the disease was immediately metastatic (37.5\% of cases). Local treatment of the primary was performed in 6 patients (75\%). This consisted of radiotherapy in 3 patients and surgery followed by salvage radiotherapy in 3 patients. Hormonal castration was performed in all patients.

Table 1. Characteristics of patients with castration-resistant prostate cancer in oligoprogression.

\begin{tabular}{|c|c|}
\hline At the time of diagnosis & Staff (percent) \\
\hline Median age, year & $70(56-79)$ \\
\hline median PSA, ng/ml & $25.1(4.9-3609)$ \\
\hline Metastatic disease, $\mathrm{n}(\%)$ & $3(37.5)$ \\
\hline Local treatment of the primary disease, $\mathrm{n}(\%)$ & $6(75)$ \\
\hline Androgenic castration, $\mathrm{n}(\%)$ & $8(100)$ \\
\hline \multicolumn{2}{|l|}{ At the time of oligoprogression } \\
\hline Median age, year & $73(60-81)$ \\
\hline median PSA, ng/ml & $3.11(2.5-43.8)$ \\
\hline \multicolumn{2}{|l|}{ Diagnostic imaging, $\mathrm{n}(\%)$} \\
\hline PET-CT (PSMA/Choline) & $8(100)$ \\
\hline Conventional imaging & $1(12.5)$ \\
\hline \multicolumn{2}{|l|}{ Number of progressive lesions, $\mathrm{n}(\%)$} \\
\hline 1 & $7(87.5)$ \\
\hline 2 & $1(12.5)$ \\
\hline \multicolumn{2}{|l|}{ Types of progressive lesions, $\mathrm{n}(\%)$} \\
\hline Bone & $8(87.5)$ \\
\hline Local relapse & $1(12.5)$ \\
\hline \multicolumn{2}{|l|}{ Treatment, $\mathrm{n}(\%)$} \\
\hline Radiotherapy & $8(100)$ \\
\hline \multicolumn{2}{|l|}{ Radiotherapy technique } \\
\hline Stereotaxis & $7(77.77)$ \\
\hline $3 \mathrm{D}$ & $2(22.23)$ \\
\hline \multicolumn{2}{|l|}{ Fractionation, $\mathrm{n}$ lesion } \\
\hline $10 \mathrm{~Gy} \times 3$ fractions & $6(1)$ \\
\hline $4 \mathrm{~Gy} \times 5$ fractions & $1(1)$ \\
\hline $12 \mathrm{~Gy} \times 3$ fractions & $1(1)$ \\
\hline $23 \mathrm{~Gy} \times 2$ fractions & $1(1)$ \\
\hline
\end{tabular}




\subsection{At the Time of Diagnosis of Oligoprogressive Castration-Resistant Prostate Cancer (Table 1)}

The median age at diagnosis of oligoprogression was 73 years with a median PSA level of $3.11 \mathrm{ng} / \mathrm{ml}$. Diagnosis of progression was performed by PSMA PET. One patient had an initial CT scan before PSMA PET. Imaging had revealed 9 lesions, two of which were in one patient. There were 8 bone lesions $(87.5 \%)$ and 1 local relapse (12.5\%). All lesions were treated by external radiotherapy, 7 of which were treated by stereotaxis $(77.77 \%)$ and 2 by three-dimensional conformal technique (22.23\%). Various treatment regimens were used: 20 Gy in 5 fractions on one lesion, $30 \mathrm{~Gy}$ in 3 fractions on six lesions, $36 \mathrm{~Gy}$ in 3 fractions on one lesion, $46 \mathrm{~Gy}$ in 2 fractions on one lesion with no side effects. Systemic treatment was continued before, during and after radiotherapy. Seven patients (87.5\%) had a single line of hormone therapy and one patient had Docetaxel in addition to hormone therapy.

\subsection{Oncological Outcomes after Radiotherapy of Oligoprogressive Castration-Resistant Prostate Cancer (Table 2)}

The median follow-up of patients after ablative or conformal stereotactic radiotherapy was 12.5 months (min 5; max 93). Seven patients showed a biochemical response to treatment with a median decrease in PSA of $67 \%$. One patient was non-responder to treatment with a rise in PSA following radiotherapy. Median progression-free survival (PFS) was 7 months ( $\min 2$; max 75) (Figure 1). Median survival without the need for further systemic therapy was 9 months (min 3; max 75) (Figure 2). During the follow-up period, six patients received secondgeneration hormone therapy to treat their relapse, and the remaining two did not show clinical or biochemical relapse.

\section{Discussion}

The prognosis of oligometastatic prostate cancer is approximately equal to that of non-metastatic prostate cancer [11]. However, there is a difference in survival depending on the number and location of metastases. Indeed, the SEER (Surveillance, Epidemiology, and End Results -Medicare insurance program-linked database) study showed that in terms of overall survival and progression-free survival, patients with a single metastatic site had a better prognosis. It also showed that lymph node sites were better than bone sites [12].

In our study, we found 9 progressive lesions, 8 of which were bone lesions and 1 local relapse.

The diagnostic methods are diverse but have different sensitivities depending on the PSA level. For a PSA of less than $7 \mathrm{ng} / \mathrm{ml}$, scintigraphy has almost no sensitivity. Dynamic examinations such as choline PET and PSMA PET allow the diagnosis of recurrence and micro metastases (respectively $90 \%$ and $97 \%$ for a PSA level above $2 \mathrm{ng} / \mathrm{ml}$ ) [13] [14]. The median PSA level at oligoprogression was $3.11 \mathrm{ng} / \mathrm{ml}$. All oligoprogressive lesions were diagnosed by PET-PSMA. 
Table 2. Oncological outcomes after radiotherapy of oligoprogressive castration-resistant prostate cancer.

\begin{tabular}{|c|c|}
\hline Response n (\%) & \\
\hline Yes & $7(87.5)$ \\
\hline No & $1(12.5)$ \\
\hline Need for 2nd generation hormone therapy after radiotherapy, n (\%) & $6(75)$ \\
\hline Median follow-up (months) & $12.5(5-93)$ \\
\hline Median survival without 2 nd line hormone therapy (months) & $9(3-75)$ \\
\hline Median progression-free survival (months) & $7(2-75)$ \\
\hline
\end{tabular}

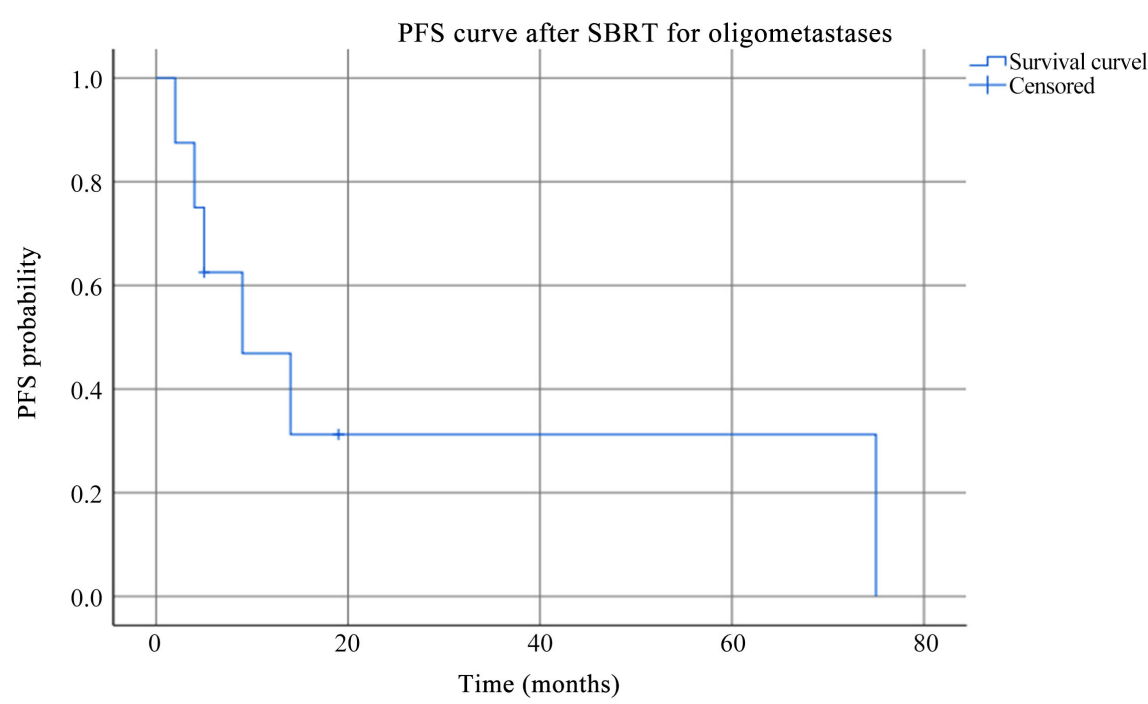

Figure 1. Progression-free survival curve after radiotherapy of oligoprogressive castration-resistant prostate cancer.

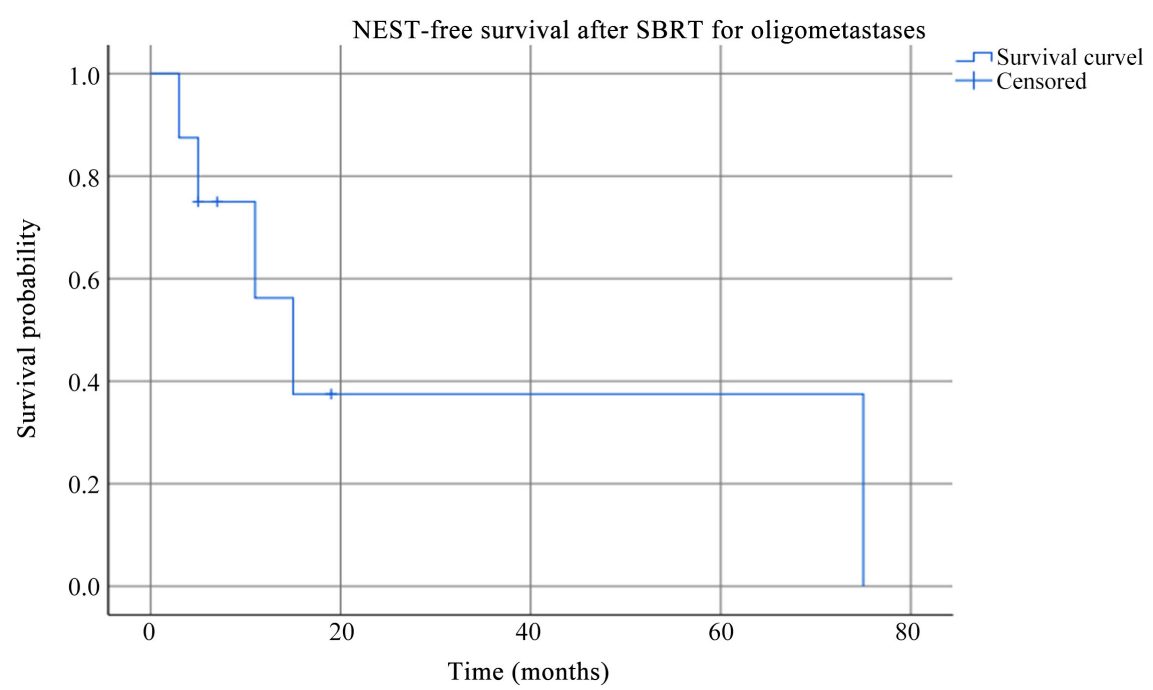

Figure 2. Survival curve without second generation hormone therapy after radiotherapy of oligoprogressive castration-resistant prostate cancer. 
In case of oligoprogression, there are different treatment strategies [15]:

- modification of systemic treatments;

- continuation of current systemic therapy if progression is considered minim-

al;

- management of metastatic progression with radical local treatment, such as stereotactic radiotherapy, to extend the time frame without modification of systemic treatments.

Our approach was to treat all oligoprogressive lesions radically with stereotactic and conformal radiotherapy while retaining systemic treatment.

The natural history of metastatic prostate cancer shows that the clinical benefit of systemic treatment is $2-3$ years. Switching to second-generation hormone therapy when oligoprogression of castration-resistant prostate cancer occurs is the standard of care. The use of radiotherapy in oligoprogression is not a defined standard, but specialists use it. Radiotherapy is mainly used for bone or lymph node lesions found on dynamic examinations (choline PET, PSMA PET). The fractions and doses vary from one study to another [16]. A retrospective, multicentre observational study showed a progression-free survival after radiotherapy of 12.3 months over a median follow-up of 30.7 months [17]. The study by Charlien et al. found a progression-free survival requiring second-generation hormone therapy of 10 months after a follow-up of 18 months [6]. In our study, after a median follow-up of 12.5 months, we found a progression-free survival requiring second-generation hormone therapy of 9 months (6 patients). The results in terms of survival without second-generation hormone therapy are similar to those of Charlien et al. [6]. The role of radiotherapy on oligoprogressive lesions in oligoprogressive prostate cancer has yet to be defined because the studies conducted to date are insufficient [18].

The limitations of our study are that it is a retrospective study with a very small number of patients. Nevertheless, the results confirm the very rare poor data in the literature.

\section{Conclusions}

The standard treatment for oligoprogressive castration-resistant prostate cancer is second-generation hormone therapy.

However, this systemic treatment is not available in all countries, especially in the developing world.

Radiotherapy may be an alternative and a prospective study could validate this therapeutic approach.

\section{Conflicts of Interest}

The authors declare no conflicts of interest regarding the publication of this paper.

\section{References}

[1] Freddie, B., Ferlay, J., Soerjomataram, I., Siegel, R.L., Torre, L.A. and Jemal, A. 
(2018) Global Cancer Statistics 2018: GLOBOCAN Estimates of Incidence and Mortality Worldwide for 36 Cancers in 185 Countries. CA: A Cancer Journal for Clinicians, 68, 394-424. https://doi.org/10.3322/caac.21492

[2] Baldari, S., Boni, G., Bortolus, R., Caffo, O., Conti, G., De Vincentis, G., et al. (2017) Management of Metastatic Castration-Resistant Prostate Cancer: A Focus on Radium-223. Critical Reviews in Oncology/ Hematology, 113, 43-51. https://doi.org/10.1016/j.critrevonc.2017.03.001

[3] International Agency for Research on Cancer. Fact Sheets by Cancer. http://globocan.iarc.fr/Pages/fact sheets cancer.aspx?cancer=prostate

[4] Hellman, S. and Weishselbaum, R.R. (1995) Oligometastases. Journal of Clinical Oncology, 13, 8-10. https://doi.org/10.1200/JCO.1995.13.1.8

[5] Annede, P. and Chargari, C. (2019) Oligométastases et oligoprogressions: Concepts et histoire naturelle. Cancer/Radiothérapie, 23, 475-481.

https://doi.org/10.1016/j.canrad.2019.07.141

[6] Berghen, C., Joniau, S., Ost, P., Poels, K., Everaerts, W., Everaerts, W., et al. (2019) Progression-Directed Therapy for Oligoprogression in Castration-Refractory Prostate Cancer. European Urology Oncology, 4, 305-309. https://doi.org/10.1016/j.euo.2019.08.012

[7] Morton, D.L. and Yao, K. (2003) Surgical Treatement of Pulmonary Mestastases in the Holl-Frei Cancer Med 6th Ed.

https://www.ncbi.nlm.nih.gov/books/NBK6/

[8] Pastorino, U., Buyes, M., Friedel, G., Ginsberg, R.J., Girard, P., Goldstraw, P., et al. (1997) Long-Term Results of Lung Metastasectomy: Prognostic Analyses Based on 5206 Cases. Journal of Thoracic and Cardiovascular Surgery, 113, 37-49. https://doi.org/10.1016/S0022-5223(97)70397-0

[9] Tanvetyanon, T., Robinson, L.A., Schell, M.J., Strong, V.E., Kapoor, R., Coit, D.G., et al. (2008) Outcomes of Adrenalectomy for Isolated Synchronous versus Metachronous Adrenal Metastases in Non Small Cell Lung Cancer: A Systematic Review and Pooled Analysis. Journal of Clinical Oncology, 26, 1142-1147.

https://doi.org/10.1200//CO.2007.14.2091

[10] Theodorescu, D. and Krupsky, T.L. (2009) Prostate Cancer-Biology, Diagnosis, Pathology, Staging, and Natural History. Emedicine, Updated: Feb 02, 2021.

[11] Singh, D., Yi, W.S., Brasacchio, R.A., Muhs, A.G., Smudzin, T., Williams, J.P., et al. (2004) Is There a Favorable Subset of Patients with Prostate Cancer who Develop Oligometas-Tases? International Journal of Radiation Oncology, Biology, Physics, 58, 3-10. https://doi.org/10.1016/S0360-3016(03)01442-1

[12] Gandaglia, G., Karakiewicz, P.I., Briganti, A., Passoni, N.M., Schiffmann, J., Trudeau, V., et al. (2015) Impact of the Site of Metastases on Survival in Patients with Metastatic Prostate Cancer. European Urology, 68, 325-334.

https://doi.org/10.1016/j.eururo.2014.07.020

[13] Evangelista, L., Zattoni, F., Guttilla, A., Saladini, G., Zattoni, F., Colletti, P.M., et al. (2013) Choline PET or PET/CT and Biochemical Relapse of Prostate Cancer: A Systematic Review and Meta-Analysis. Clinical Nuclear Medicine, 38, 305-314. https://doi.org/10.1097/RLU.0b013e3182867f3c

[14] Beresford, M.J., Gillatt, D., Benson, R.J. and Ajithkumar, T. (2010) A Systematic Review of the Role of Imaging before Salvage Radiotherapy for Post-Prostatectomy Biochemical Recurrence. Clinical Oncology, 22, 46-55.

https://doi.org/10.1016/j.clon.2009.10.015

[15] Cheung, P. (2016) Stereotactic Body Radiotherapy for Oligoprogressive Cancer. 
British Journal of Radiology, 89, Article No. 1066. https://doi.org/10.1259/bjr.20160251

[16] Palacios-Eito, A., Bejar-Luque, A., Rodriguez-Linan, M. and Garcia-Cabezas, S. (2019) Oli-Gometastases in Prostate Cancer: Ablative Treatment. World Journal of Clinical Cases, 10, 38-51. http://doi.org/10.5306/wjco.v10.i2.38

[17] Triggiani, L., Mazzola, R., Magrini, S.M., Ingrosso, G., Borghetti, P., Trippa, F., et al. (2019) Metastasis-Directed Stereotactic Radiotherapy for Oligoprogressive Castration-Resistant Prostate Cancer: A Multicenter Study. World Journal of Urology, 37, 2631-2637. https://doi.org/10.1007/s00345-019-02717-7

[18] Beauval, J.-B., Loriot, Y., Hennequin, C., Rozet, F., Barthelemy, P., Borchiellini, D. et al. (2018) Loco-Regional Treatment for Castration-Resistant Prostate Cancer: Is There Any Rationale? A Critical Review from the AFU-GETUG. Critical Reviews in Oncologyl Hematology, 122, 144-149.

https://doi.org/10.1016/j.critrevonc.2017.12.012

\section{Abbreviations}

SBRT: stereotactic radiotherapy

NEST: second-generation hormone therapy

PFS: progression-free survival

PSA: prostate specific antigen

Gy: Gray

PET-PSMA: positron emission tomography-Prostate specific membrane antigen 